\title{
HOW MUCH DOES THE ENVIRONMENT CONTRIBUTE TO CANCER?
}

In its broadest sense, the environment can be defined as external conditions influencing the development of people, animals or plants. For the purpose of studying the effects of the environment on human health, a distinction is often made between conditions from which individuals may have no or only partial control and those for which some element of personal choice exists. Exposure encountered at work and to substances in air and water would, for example, tend to fall in the former category, while "lifestyle" factors such as smoking, eating a high fat diet, and drinking alcohol would come in the latter. Higginson" points out that, in the public mind "environmental cancer" is a term often limited to cancers resulting from chemical exposures, especially manmade, although most research workers use it in the wider sense to cover all conditions that impact on human cancer.

This paper gives an overview of environmental causes of cancer and the approaches used in the investigations of this issue, discusses the controversies and challenges, and outlines some of the emerging scientific methodology.

\section{CARCINOGENICITY}

The International Agency for Research into Cancer (IARC) classifies carcinogenic substances into four groups according to the evidence (table 1). For human data, sufficient evidence is defined as the establishment of a causal relation between exposure to the agent and human cancer. Limited evidence is defined as the observation of a positive association between exposure to the agent and human cancer, for which a causal interpretation is considered credible, but chance, bias or confounding could not be ruled out with reasonable confidence. Similar definitions relate to the evidence from experimental data (see the IARC monographs on the evaluation of carcinogenic risks to humans for a full description, for example ${ }^{2}$ ).

In the USA, a biannual report on carcinogens is published as part of the US National Toxicology Program (http://ntp-server.niehs.nih.gov/NewHomeRoc/AboutRoC.html). A brief scientific evaluation is provided of the animal and human evidence for each substance, together with information on the use, exposure routes, and levels of substances which are (1) known to be human carcinogens - that is, for which there is sufficient evidence from human studies that indicates a causal relation between exposure to the substance and human cancer; and (2) reasonably anticipated to be human carcinogens - that is, for which there is limited evidence of carcinogenicity in humans and/or sufficient evidence of carcinogenicity in experimental animals.

The IARC classification and the National Toxicology Program have tended (although not exclusively) to be applied to individual chemicals rather than to complex mixtures of substances, such as cigarette smoke, or to groups of substances such as volatile organic compounds. Other less well defined factors (see below) which have been shown to influence cancer risk, and which also do not fit easily into this categorisation, include being overweight and eating a high fat diet.

Many different sources, processes, and pathways can lead to exposure to an environmental hazard. Figure 1, adapted from Briggs, ${ }^{3}$ shows some of the elements involved in the process from source to heath effect. Humans are exposed to a wide range of potential natural or synthetic toxicants, and frequently to a multitude of complex mixtures. Many studies have a tendency to focus on a limited range of environmental influences, often because of the restricted nature of the group under investigation-for example, in specific employment sectors—or because of difficulties in obtaining information on the wider environment. A more holistic approach is needed, however, with consideration of estimates of total body burden to potential carcinogenic substances, in order to set specific environmental influences in context and to inform the development of effective risk reduction strategies.

For example, Samet, ${ }^{4}$ in discussing the health effects of radiation, points out that although exposure occurs through the use of radiation for medical and industrial purposes and from accidents and nuclear weapons, most of the dose received by the general population comes from natural sources, including cosmic rays, terrestrial radiation, and internally deposited radionuclides, with radon being by far the largest contributor to population dose. 


\begin{tabular}{|c|c|c|}
\hline Group & Definition & Used when \\
\hline 1 & Carcinogenic to humans & Evidence is sufficient \\
\hline $2 \mathrm{~A}$ & Probably carcinogenic to humans & Limited evidence in humans, and sufficient evidence in experimental animals, \\
\hline $2 B$ & Possibly carcinogenic to humans & $\begin{array}{l}\text { Limited evidence in humans, and absence of sufficient evidence in experimental animals, or } \\
\text { inadequate evidence in humans or human data non-existent and sufficient evidence in } \\
\text { experimental animals }\end{array}$ \\
\hline 3 & Not classifiable as to carcinogenicity to humans & Not classifiable to any other group \\
\hline 4 & Probably not carcinogenic to humans & Evidence suggests a lack of carcinogenicity in humans and in experimental animals \\
\hline
\end{tabular}

Different kinds of research contribute relevant information to the study of the causes of cancer. Toxicological studies conducted on experimental animals can rigorously assess the biological response to a range of levels of exposure to a given substance or combination of substances. This has the advantage of specificity but presents a problem when extrapolating to humans.

Clinical studies employing human volunteers have limited use as these can only test response to a narrow range of exposure levels. Epidemiological methods have thus been widely utilised to test causal hypotheses in human cancer, both in specific groups defined-for example, by occupation-or in the more general population. Higginson ${ }^{5}$ points out that such studies have limitations including: (1) a lack of sensitivity to detect very low risks; (2) difficulty in discriminating between several plausible risk factors in complex situations; (3) the inability to evaluate the impact of recent exposures; and (4) uncertainty in interpreting "negative" studies or inverse relationships.

Nevertheless, Doll ${ }^{6}$ points out that epidemiological studies have drawn attention to most of the risks that have so far been recognised as causing large numbers of cancers throughout the world, and have the advantage that, when a cause has been established, they provide an indication of the size of the effect.

\section{FACTORS CONTRIBUTING TO CANCER}

In 1981, Doll and Peto ${ }^{7}$ published a seminal review of the trends and causes of cancer. They concluded that there was good evidence that cancer is largely an avoidable disease, but, with some important exceptions, there was greater uncertainty regarding the most effective ways of avoiding a large proportion of cancers. Table 2 shows the proportion of cancer deaths attributed by Doll and Peto to various factors. They comment that geophysical factors are responsible for a much greater number of non-fatal cancer cases because of the importance of ultraviolet (UV) light in causing skin cancers. Although there have been great advances in cancer research in the 20 years since this paper, the broad conclusions are generally agreed to still hold. There is universal agreement that tobacco is the most important preventable cause of cancer and causes one third of all cancer deaths in developed countries. $\mathrm{Peto}^{8}$ in a recent paper estimated separately for current smokers (S) and non-smokers (NS) the percentage of future cancer deaths in the USA that would be avoided by successively removing the effects of smoking $(60 \%(S))$, known infections (2\% (S), 5\% (NS)), alcohol (0.4\% (S), 1\% (NS)), sunlight $(0.4 \%$ (S), $1 \%$ (NS)), current occupational and environmental pollution $(0.8 \%$ (S), $2 \%$ (NS)), inactivity $(0.4 \%$ (S), $1 \%(\mathrm{NS}))$, and obesity (4\% (S), 10\% (NS)). He comments "it is absurd for smokers in the West to worry about anything except stopping smoking". Peto estimates, however, that at present about a quarter of cancers in current smokers and half in nonsmokers are unavoidable.

Risk factors vary for cancers of specific sites, as shown in table 3, adapted from Tominaga. ${ }^{9}$ Although Doll and Peto attribute only a small proportion of cancer deaths to occupational exposure, the largest group, over 25, of chemicals or processes classified into IARC group 1 as representing a carcinogenic hazard to humans are based on evidence largely from studies of occupational groups. ${ }^{1}$ The progressive reduction of exposure levels to many occupational hazards has been achieved through regulation and has largely ensured that occupational exposures will contribute only a small proportion of future cancer incidence. The exception is the widespread use of asbestos in the construction industry from the 1950s to the mid 1970s. This has resulted in an epidemic of mesothelioma and increasing incidence, with approximately 250000 mesothelioma deaths forecast for the period 1995 to 2029. ${ }^{10}$

The factor given the highest attribution to cancer deaths by Doll and Peto was diet. However, this factor also had the widest range of acceptable estimates, from $10-70 \%$. The influence of diet is notoriously complex and difficult to study, due to the variety of foods and their many constituents and changing patterns of consumption. ${ }^{811}$ Drinking alcohol and consuming foods contaminated with aflatoxins have been established as clear risk factors for some cancer sites. Alcoholic beverages cause inflammation and cirrhosis of the liver, leading to liver cancer. Alcohol has been shown to be an important cause of oral and oesophageal cancer, interacts with smoking, and may also contribute to colorectal cancer. The influence of other aspects of diet is less equivocal. For example, a high intake of red meat has been associated in some studies with increased risk from several cancers such as stomach, colon, and rectum. ${ }^{11} \mathrm{~A}$ diet rich in fresh fruits and vegetables has been related to reduced risk of several cancers-for example, digestive tract, stomach, hormone related cancers-and whole grain food intake has been consistently related to reduced risk of colorectal cancer and several other sites. There remains considerable debate on the issue of fats and of specific types of fats, on the risk of colorectal, breast and other cancers, with the suggestion that substitution of saturated fats with unsaturated fats or olive oil reduces risk.

There is a general consensus that, notwithstanding the constituents of a diet, cancer is more frequent in those who are overweight, particularly for post-menopausal breast cancer and cancers of the endometrium, gall bladder, and kidney. Peto $^{8}$ suggests that about 5\% of all cancers in the European Union might be prevented if the body mass index of the whole population was below $25 \mathrm{~kg} / \mathrm{m}^{2}$.

Contamination of food by environmental chemicals such as dioxins, polychlorinated biphenyls (PCBs) (see also later section on waste management), and pesticide residues is of considerable public concern. It has been established that the food 
Potential sources

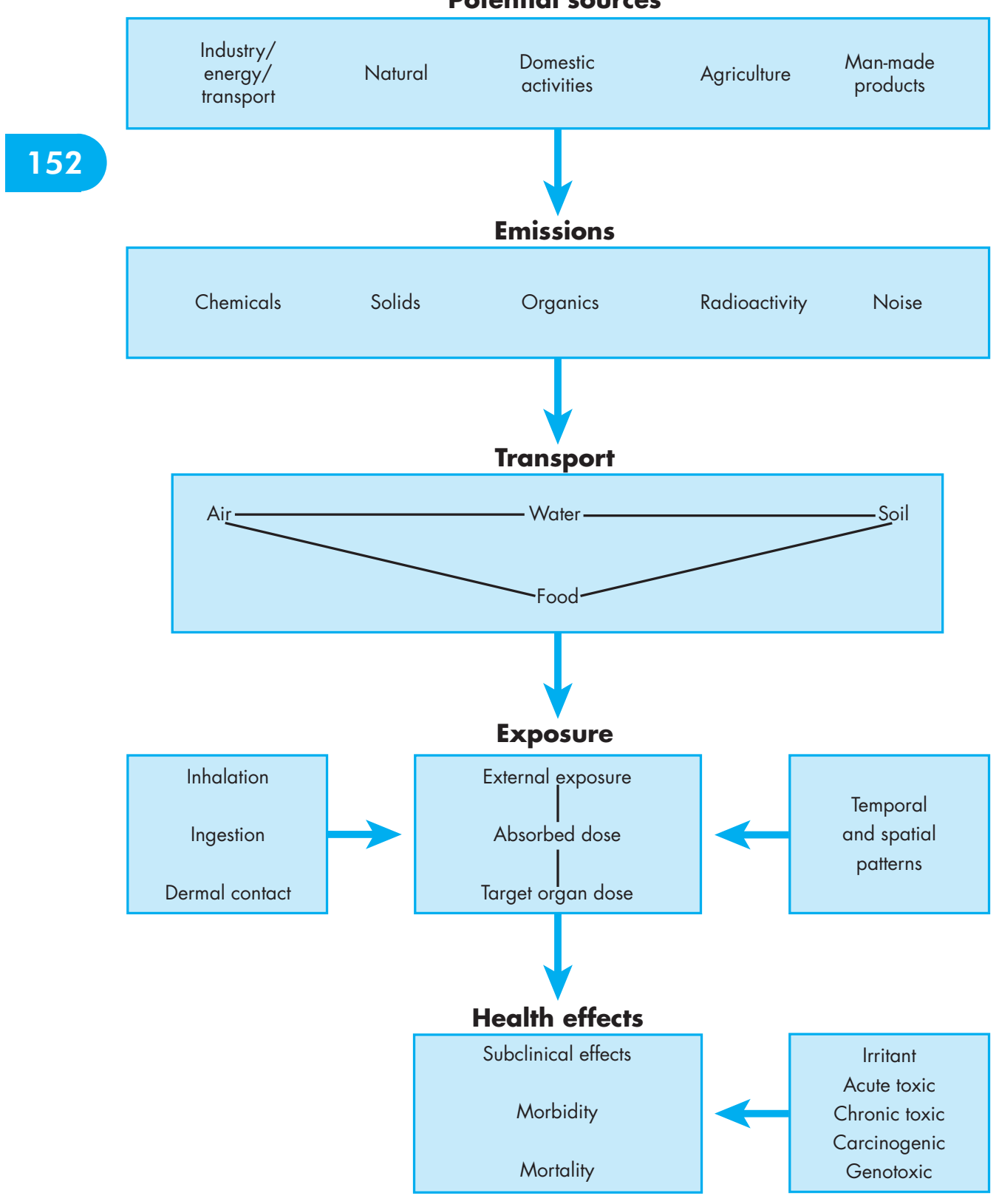

Figure 1 Elements included in the process of identifying environmental carcinogens, from source to health effect. chain is the primary pathway of human exposure to dioxins and PCBs, particularly from meat, dairy products, and fish. The widespread exposure to these substances can be exemplified from the fact that they can be detected in most human adipose tissue. They are also present in breast milk and, on a body weight basis, the intake of breast fed babies has been estimated to be one or two orders of magnitude higher than the average adult intake. IARC has classified dioxin as a human carcinogen (group 1) based on limited evidence in humans and sufficient evidence in experimental animals as well as on mechanistic considerations.

A large range of pesticides is widely used in the production of food and the potential harmful effects from pesticide residues in foodstuffs continue to raise public concern. Current regulation of pesticides should ensure that substances that are shown to be carcinogenic do not reach or are withdrawn from the market. However, compounds such as some chlorinated organic pesticides (for example, DDT) were used extensively in the 1950s and 1960s. These organochlorine compounds have long persistence in the environment and in animal tissues. The presence of metabolites in human tissue has been suggested to be an aetiological factor in the development of some cancers-for example, breast cancer.

\section{ENVIRONMENTAL POLLUTION}

The proportion of cancers attributed by Doll and Peto to environmental pollution is even smaller than that for occupation.

\section{Ambient air pollution}

There have been many studies of cancer and air pollution, particularly ambient air (reviewed by Rushton ${ }^{12}$ ). For example, urban air contains thousands of chemicals and Cohen and Pope $^{13}$ suggest that lung cancer, in particular, may be increased by ambient air pollution, chiefly due to the incomplete combustion of fossil fuels. A considerable number of studies have compared lung cancer rates in urban and rural residents 


\section{Table 2 Proportions of cancer deaths attributed to} various different factors

\begin{tabular}{lcl}
\hline & \multicolumn{2}{c}{ Percentage of all cancer deaths } \\
\cline { 2 - 3 } Factor or class of factors & $\begin{array}{l}\text { Best } \\
\text { estimate }\end{array}$ & $\begin{array}{l}\text { Range of acceptable } \\
\text { estimates }\end{array}$ \\
\hline Tobacco & 30 & $25-40$ \\
Alcohol & 3 & $2-4$ \\
Diet & 35 & $10-70$ \\
Food additives & $<1$ & $-5^{*}$ to -2 \\
Reproductive and sexual behaviour & 7 & $1-13$ \\
Occupation & 4 & $2-8$ \\
Pollution & 2 & $<1-5$ \\
Industrial products & $<1$ & $<1-2$ \\
Medicines and medical procedures & 1 & $0.5-3$ \\
Geophysical factors & 3 & $2-4$ \\
Infection & $10 ?$ & $1-?$ \\
Unknown & $?$ & $?$ \\
\hline
\end{tabular}

${ }^{*}$ Allowing for a possibly protective effect of antioxidants and other preservatives.

of the same country, or lung cancer rates for urban areas stratified according to population size, and have showed increased incidence in urban areas. This relationship has been further explored in a series of studies of changes in lung cancer experience of immigrants to various countries. For example, several investigations on emigrants from the UK to New Zealand showed that, in general, the lung cancer rates of emigrants were lower than that of residents in the UK but higher than those born in the new country. It has been suggested that this reflects a lasting effect of early environment on lung cancer mortality later in life.

Some environmental studies have indicated that lung cancer is more closely related to sulfates as an index of air pollution than fine particles and this is supported by studies of occupational groups and animal experiments. Other constituents of air that have been associated with increased lung cancer include asbestos, polycyclic hydrocarbons, and diesel exhaust. The evaluation of the role of air pollution in the aetiology of other cancers is even more equivocal than for lung cancer. Associations have been suggested, for example, with digestive and gastrointestinal tract cancers, bladder cancer, oesophageal cancer, and breast cancer.

\section{Indoor air}

In addition to ambient air pollution, the potential contribution of indoor air pollution, particularly environmental tobacco smoke to the risk of lung cancer, has been increasingly recognised as important, ${ }^{13}$ given that, in developed countries, many

\section{Table 3 Examples of site specific risk factors}

\begin{tabular}{|c|c|c|}
\hline Risk factors & $\begin{array}{l}\text { Selected chemicals or occupations } \\
\text { classified as IARC group } 1 \text { carcinogens }\end{array}$ & Major cancer sites \\
\hline Tobacco & & $\begin{array}{l}\text { Oropharynx, larynx, lung, oesophagus, stomach, pancreas, liver, ureter, } \\
\text { bladder, cervix }\end{array}$ \\
\hline Betel quid & & Oropharynx, oesophagus \\
\hline $\begin{array}{l}\text { Diet } \\
\text { Fat/calorie } \\
\text { Dietary fibre } \\
\text { Salt } \\
\text { Vegetables/fruits* }\end{array}$ & Aflatoxins & $\begin{array}{l}\text { Colon, breast? prostate? } \\
\text { Colon } \\
\text { Stomach } \\
\text { Stomach and other organs }\end{array}$ \\
\hline \multicolumn{3}{|l|}{ Infection } \\
\hline $\begin{array}{l}\text { Viruses } \\
\text { HBV/HCV } \\
\text { HPV/HSV-2 } \\
\text { EBV } \\
\text { HTLV-1 }\end{array}$ & & $\begin{array}{l}\text { Liver } \\
\text { Cervix } \\
\text { Lymphatic system, nasopharynx } \\
\text { Haemato-lymphatic system (T cells) }\end{array}$ \\
\hline $\begin{array}{l}\text { Parasites } \\
\text { Schistosomiasis haematobium } \\
\text { Opisthorchis viverrini } \\
\text { Clonorchis scinensis } \\
\text { Bacteria }\end{array}$ & & $\begin{array}{l}\text { Urinary bladder } \\
\text { Liver (cholangioma) } \\
\text { Liver }\end{array}$ \\
\hline Helicobacter pylori & & Stomach \\
\hline Reproductive factors & & Breast \\
\hline Occupation & $\begin{array}{l}\text { Auramine } \\
\text { Coal tar } \\
\text { Iron and steel founding } \\
\text { Mineral oils } \\
\text { Mustard gas } \\
\text { Nickel }\end{array}$ & Lung, skin, bladder \\
\hline Alcohol & & Oropharynx, oesophagus, colon-rectum?, breast? \\
\hline Sunlight/radiation & & Skin \\
\hline Pollution & Arsenic and arsenic compounds & Lung \\
\hline Medicine and medical procedures & $\begin{array}{l}\text { Oestrogen replace therapy } \\
\text { Oral contraceptives }\end{array}$ & Haematopoietic system, breast \\
\hline Sexual behaviour & & Cervix \\
\hline \multicolumn{3}{|l|}{ Industrial products } \\
\hline \multicolumn{3}{|l|}{ Food additives } \\
\hline Obesity & & Breast \\
\hline Exercise* & & Colon-sigmoid \\
\hline Stress & & Stomach \\
\hline
\end{tabular}


people spend up to $90 \%$ of their time indoors. Levels of substances in indoor air are related to levels outdoors, the activities of the occupants (for example, smoking, cooking), fitting and furnishings (for example, formaldehyde in insulating materials), and the geographical location (for example, radon). The contribution of environmental tobacco smoke and radon (see below) on the incidence of lung cancer has been estimated to be considerable, with approximately $2 \%$ of lung cancer deaths occurring in non-smokers. ${ }^{8}$ The source of formaldehyde, classed by IARC as a group $2 \mathrm{~A}$ probable human carcinogen, in indoor air is mainly from furnishing materials and cigarette smoke. Levels indoors have been shown to be 10 times greater than levels outdoors. ${ }^{14}$

\section{Water}

There are numerous studies relating to water pollution, especially the byproducts of chlorination, although the evidence that water pollution is an important factor in human cancer is unconvincing. ${ }^{1}$ Potential contaminants of concern include arsenic, which at high doses has been shown to cause skin cancer when ingested. The byproducts of chlorination of water-primarily halogenated organic compounds, including trihalomethanes such as chloroform-have been associated with an increased risk of both bladder and rectal cancers, ${ }^{15}$ although the influence of diet was not explored in these studies.

\section{Radiation}

Exposure to all forms of radiation, including ionising radiation, UV light, and low frequency sources, causes public concern. Doll ${ }^{16}$ suggests that ionising radiation may cause up to $4 \%$ of all cancers, mostly as a result of natural radiation from radon and cosmic rays, external radiation from radionuclides in rocks, soils, and building materials, and internal radiation from naturally radioactive traces in food. Radon concentrations indoors vary greatly depending on local geological characteristics. Estimates of annual cancer deaths caused by indoor radon exposure also vary widely. Doll ${ }^{16}$ suggests that up to $6 \%$ of lung cancer in the general populations may be due to radon and that action to reduce the risk is advisable.

UV light from sunlight exposure is responsible for a large number of skin cancers, including melanomas and basal cell and squamous carcinomas. Squamous carcinomas appear to be related to cumulative exposure to UV light while melanoma, which has been steadily increasing in all white skinned populations for many years, is associated with frequency of sunburn. There is also evidence to suggest a relation between UV light and the risk of non-Hodgkin's lymphoma and chronic lymphatic leukaemia, with squamous cell carcinomas and melanomas being found to be much more common than would be expected after the occurrence of nonHodgkin's lymphoma and chronic lymphatic leukaemia. Doll ${ }^{16}$ suggests that, if the relation is confirmed in other studies, it might be explained by the effect of UV light on the immune system, strengthening even more the need to avoid unnecessary exposure to UV light.

Electromagnetic fields experienced through living near cables, radio and telegraph operations, and other sources have been a topic of increasing public concern, particularly in relation to emissions from mobile phones and from the base stations that receive and transmit the signals. An expert group which examined the possible effects of these sources of radiation ${ }^{17}$ concluded that exposures of the general population from base stations emissions and other emitting sources such as antennae for radio, television, and paging are well below guideline values. The levels of exposure arising from phones held near the head are, however, substantially greater than these.

Cognitive tests on volunteers have found that mobile phone signals shorten reaction times in some tasks. It has been suggested that these reflect the effect of small temperature increases on synaptic transmission in the region of cerebral cortex directly under the headset antenna. To date, few epidemiological studies have directly examined the relation of mobile phones to morbidity or mortality, and none has explored the effects from base stations, although there have been several ecological studies of this aspect. Overall the evidence to date does not indicate that risks are increased, although many studies lack statistical power and some have methodological deficiencies. The expert group recommended a range of issues that needed further urgent research.

\section{Waste management activities}

The vast amount of household and commercial waste, together with smaller quantities of industrial and specialised wastes, including that from hospitals, is disposed of mainly through incineration or in landfill sites. The potential health effects of substances emanating from both these sources have been the subject of many studies. Incineration can give rise to a wide range of gases and aerosols, including fine particulate matter and a large number of metals and organic chemicals, many of which have potential toxic properties. Highest public concern has been raised about dioxins, PCBs, and polycyclic aromatic hydrocarbons (PAHs). A report by the Institute for Environment and Health ${ }^{18}$ reviewed the 10 pollutants most likely to be produced in amounts sufficient to exceed air quality standards or to be of concern because of their toxicity. Established or potential carcinogenic compounds included cadmium, arsenic, chromium, nickel, dioxins, PAHs, and PCBs. Although many of these compounds have been shown to be carcinogenic in occupational studies with high levels of exposure, the evidence of cancer risk at the much lower levels resulting from incineration is either lacking or equivocal.

The health of populations living near waste landfill sites has been reported in a number of ecological studies. ${ }^{19}$ A general limitation of many of these studies is the imprecise information on exposures from the sites through the use of surrogate measures such as distance from a site. Very few collect data on specific substances or confounding factors. The evidence for a causal relation between landfill exposures and cancers is weak, although several studies have reported excesses of bladder, lung, and stomach cancer and leukaemia.

\section{CONTROVERSIES AND CHALLENGES}

In a report of the President's Cancer Panel conference on avoidable causes of cancer held in 1994, Davis and Muir ${ }^{20}$ suggest that studying the effects of environmental pollution remains one of the most challenging areas of epidemiologic research involving large numbers of people whose exposures change over time and are often poorly characterised. A lack of exposure data is the most commonly cited factor preventing identification of a causal association between environmental and occupational risk factors and advanced health effects. ${ }^{21}$

Whatever the type of study design, the results are ultimately dependent on the quality of the data. As Higginson ${ }^{1}$ points out, global cancer statistics of good quality have now become available. ${ }^{22}$ The identification of populations exposed to environmental contaminants may be difficult because of 
inadequate identification of specific carcinogens and the distribution of contaminants in the environment, and knowledge of the duration and concentration of specific carcinogens over many years of exposure. It is also important to be able to identify sensitive population subgroups - that is, those who are particularly susceptible to the effects of a pollutant-and to be able to evaluate the variation of both individual susceptibility and individual dose.

The increasing awareness of the potential health hazards and environmental impacts of the possible pollution of the environment by man-made chemicals has led to the development of "cancerphobia"1 and the tendency to blame the environment for cancer occurrence. In a series of papers (for example, Ames and Gold, ${ }^{23}$ and Ames et $a^{24}$ ), Ames suggests that the idea that traces of synthetic chemicals are major contributors to human cancer is not supported by the evidence. After adjustment for age, and excluding lung cancer, cancer death rates in many countries are in fact showing decreasing trends. Ames emphasises the need to put the possible hazards of man made carcinogens into perspective and points out that there is an enormous background of natural chemicals (roasted coffee, for example, contains more than 1000), many of which have been shown to be rodent carcinogens. ${ }^{23}$

Ames and Gold suggest that the factors which are likely to have a major effect on reducing rates of cancer include:

- reduction of smoking

- increased consumption of fruits and vegetables

- control of infections

- avoidance of intense sun exposure

- increased physical activity

- reduced consumption of alcohol and possibly red meat.

They feel that it is important not to divert society's attention away from the few really serious hazards by the pursuit of hundreds of minor or non-existent hazards.

Davis and Muir $^{20}$ advocate the use of the "precautionary principle" - that is, society should take care not to engage in activities which appear likely to increase risks, even though uncertainty exists about the size and extent of those risks. They suggest that even though the cellular and genetic mechanisms of cancer are not fully understood, basic improvements in lifestyle, such as diet, smoking (and other drug) habits, and exercise, and in our chemical-physical environment, such as reduced toxic emissions, might have a beneficial effect on general public health, in a similar way to the improvements observed in infectious diseases occurrence in the 19th century. Multiple exposures or combinations of low levels of commonly occurring carcinogens could be part of the explanation for persisting patterns of cancer that are otherwise inexplicable.

Two divergent cancer control strategies have emerged. The first, supported by environmental activists and regulators, is to build regulatory programmes to control or eliminate pollutants in the ambient environment. The second is to direct effort into understanding the fundamental biological mechanisms of carcinogenesis, with the aim of intervening in this process through chemoprevention or treatment.

The first approach has been successfully implemented in the occupational area, where the gradual introduction of standards and exposure units has resulted in reduced levels of hazardous substances. Environmental regulation of ambient air and water has also resulted in decreasing levels of polluting substances. Logically, primary prevention of occupational and environmental carcinogens should result in lower cancer rates. The challenges facing researchers to develop appropriate methodology and carry out suitable studies to quantify changes include:
- the investigation of the relative roles of different sources of a potential carcinogen-that is, total exposure estimation

- development of epidemiological methodology to detect effects of very low levels and simultaneously evaluate the impact of potential confounding factors

- extension of knowledge of the molecular pathways and corresponding precursors of different cancers

- identification of sensitive subpopulations and evaluation of the role of individual susceptibility.

Peto $^{8}$ suggests that the rapid advances in genetic and molecular understanding will increasingly facilitate the quantification of relations between risk factors and specific events in carcinogenesis. The field of molecular epidemiology offers the opportunity to combine the scientific disciplines of epidemiology and molecular toxicology to investigate the interactions between genetic factors and environmental factors in the cause of disease. In long term studies of occupational cohorts and wider populations it has been shown that exposures to relatively high levels of established carcinogens over long periods do not affect all individuals equally. For example, only a fraction of the population of heavy smokers develops lung cancer. There is increasing evidence that genetic factors may influence an individual's susceptibility and resistance to cancer.

There is substantial inter-individual variation in genes whose products metabolise carcinogens and anti-carcinogens, repair DNA damage, and maintain cell cycle control and immune function. ${ }^{25}$ Since Doll and Peto ${ }^{7}$ published their estimates of the different causes of cancer there has been increasing research into the multiple pathways involved in the carcinogenic process and the importance of interactions. These include simultaneous exposure to both different causal and different protective factors, and host-environment (endogenous versus exogenous) interactions, including metabolic polymorphisms. Many of the genes that encode the enzymes that metabolise potential carcinogens are polymorphic-that is, there are common variant forms (prevalent in at least $1-2 \%$ of the population), resulting from genetic mutations passed down through generations. However, it should be noted that some genes may encode an enzyme that can detoxify a potential carcinogen and also act on another non-genotoxic substance to produce a carcinogen.

The investigation of genetic susceptibility can range from the identification of "high penetrance" mutations, which are rare in the general population but for which the lifetime cumulative risk of the development of cancer is very high, to "low penetrance" mutations which are relatively common but have a low relative risk. ${ }^{26}$ The latter require interaction with environmental risk factors and, because they are common, the fraction of disease caused by a particular polymorphism (that is, the attributable risk) may be substantial and thus have important public health implications. An example of a high penetrance mutation is the BRCAl gene that gives a high risk of breast cancer to the small proportion of women who are carriers. An example of the result of low penetrance mutation is the slow acetylator version of $\mathrm{N}$-acetyltransferase 2 (NAT2) that has been shown to increase the risk of bladder cancer in people exposed to arylamines. However, the fast acetylator version which "protects" from bladder cancer may also increase the risk of colon cancer.

Future research will need to incorporate measurement of susceptibility to aid the investigation of carcinogenic pathways and to detect gene-environment interactions. This will require multidisciplinary collaborative teams involving epidemiology, toxicology, and exposure assessment. Numbers of 
scientific and media reports of cancer studies have risen dramatically in the last decade. Perhaps the greatest challenge for the research community will be the requirement to communicate clearly key concepts and principles of interpretation, including the difference between a statistical association and a causal association with biological meaning..$^{27}$ The limitations and uncertainties of a study and its contribution to existing scientific evidence will facilitate the ongoing debate of identifying and correcting misperceptions about cancer risk factors. Above all, as Linet ${ }^{27}$ says, it will be important for researchers to listen more closely to the concerns expressed by members of the public, the media, and policy makers.

\section{REFERENCES}

1 Higginson J. Environmental carcinogenesis. Cancer 1993;72:971-7.

2 International Agency for Research into Cancer. IARC Monographs on the evaluation of carcinogenic risks to humans. (47). Lyon; IARC, 1989: 1-535.

3 Briggs DJ. Exposure assessment. In: Elliott P, Wakefield JC, et al, eds. Spatial epidemiology. Oxford: Oxford University Press, 2001:335-9.

4 Samet JM. Epidemiologic studies of ionizing radiation and cancer: past successes and future challenges. Environ Health Perspect 1997; 105:883-9

5 Higginson J. Changing concepts in cancer prevention: limitations and implications for future research in environmental carcinogenesis. Cancer Research 1988;48:1381-9.

6 Doll R. Purpose of the symposium In: Wald NJ, Doll R, eds. Interpretation of negative epidemiological evidence for carcinogenicity. Lyon: IARC Scientific Publications, 1985.

7 Doll R, Peto R. The causes of cancer: quantitative estimates of avoidable risks of cancer in the United States today. London: Oxford University Press, 1981.

8 Peto J. Cancer epidemiology in the last century and the next decade. Nature 2001;411:390-5.

9 Tominaga S. Major avoidable risk factors of cancer. Cancer Letters 1999; 143(suppl):S19-S23.

10 Peto J, DeCarli A, La Vecchia C, et al. The European mesothelioma epidemic. Br J Cancer 1999;79:666-72

11 Levi F. Cancer prevention: epidemiology and perspectives. Eur J Cancer 1999;35:1046-58.

12 Rushton L. Cancer and air pollution. In: Maynard RL, ed. Air pollution reviews: volume 1. The urban atmosphere and its effects. London: Imperial College, 2000:129-61.

13 Cohen AJ, Arden Pope III C. Lung cancer and air pollution. Environ Health Perspect 1995; 103(suppl 8):219-24.

14 Humfrey C, Shuker L, Harrison P. IEH assessment on indoor air quality in the home. Leicester: Institute for Environment and Health, 1996.

15 Morris RD, Audet A-M, Angelillo DDS, et al. Chlorination, chlorination by-products, and cancer: a meta-analysis. Am J Public Health 1992;82:955-63.

16 Doll R. Nature and nurture: possibilities for cancer control. Carcinogenesis 1996; 17:177-84.

17 Independent Expert Group on Mobile Phones. Mobile phones and health. Chilton: IEGMP, c/o National Radiological Protection Board, 2000

18 Humfrey C, Taylor M, Amaning K. IEH report on health effects of waste combustion products. Leicester: Institute for Environment and Health, 1997.

19 Vrijheid M. Health effects of residence near hazardous waste landfill sites: a review of epidemiologic literature. Environ Health Perspect 2000; 108:101-12.

20 Davis DL, Muir C. Estimating avoidable causes of cancer. Environ Health Perspect 1995;103(suppl 8):301-6.

21 Checkoway H. Epidemiologic evaluation of exposure-effect relationships. In: Rappaport SM, Smith TJ, eds. Exposure assessment for epidemiology and hazard control. Michigan: Lewis Publishers, 1991:67-73.

22 Parkin DM, Whelan SL, Ferlay J, et al. eds. Cancer incidence in five continents. Lyon: International Agency for Research into Cancer, 1997

23 Ames BN, Gold LS. The causes and prevention of cancer: gaining perspective. Environ Health Perspect 1997; 105:865-73.
24 Ames BN, Magaw R, Gold LS. Ranking possible carcinogenic hazards. Science 1987;236:271-9.

25 Rothman N, Wacholder S, Caporaso M, et al. The use of common genetic polymorphisms to enhance the epidemiologic study of environmental carcinogens. Biochim Biophys Acta 2001;1471:C1-10.

26 Vineis $P$, Schulte $P, M c M i c h a e l$ AJ. Misconceptions about the use of genetic tests in populations. Lancet 2001; 357:709-12.

27 Linet MS. Evolution of cancer epidemiology. Epidemiol Rev $2000: 22 ; 35-56$

\section{QUESTIONS (SEE ANSWERS ON p 80)}

Please indicate which statements are true or false

(1) Regarding the causes of cancer:

(a) tobacco is the most important preventable cause

(b) occupational and environmental factors cause a high proportion of all cancers

(c) geophysical factors are responsible for a large number of non-fatal cancer cases

(d) all aspects of diet contribute to increased cancer rates

(e) occupational exposures will continue to contribute a high proportion of future cancer incidence

(2) Air pollution

(a) air pollution has been associated with an increased risk of lung cancer

(b) lung cancer rates in urban areas are higher than in rural areas

(c) indoor air quality is not likely to contribute to cancer

(d) environmental tobacco smoke causes lung cancer

(e) air pollution definitely causes forms of cancer other than lung

(3) Radiation

(a) radiation may cause up to $4 \%$ of all cancers

(b) the most important sources of radiation are manmade

(c) radon could cause up to $6 \%$ of lung cancer

(d) frequency of sunburn is associated with basal cell and squamous carcinomas of the skin

(e) no biological effects occur from exposure to radiation from mobile phones

(4) Controversies

(a) environmental contamination by man made chemicals is thought by many to be a major contributor to cancer incidence

(b) cancer statistics support this view

(c) there are a very large number of naturally occurring carcinogens

(d) regulation has resulted in decreasing levels of polluting substances in the environment

(e) regulation will result in lower cancer rates

(5) Lower cancer rates may result from:

(a) reduction of smoking

(b) reduction of consumption of fruits and vegetables

(c) increased physical activity

(d) developing a good suntan

(e) eating less red meat 